\title{
Evaluation of Specialty Drug Price Trends Using Data from Retrospective Pharmacy Sales Transactions
}

\author{
Robert Penington, PharmD, MS, MBA, and Jo Ann Stubbings, BSPharm, MHCA
}

\begin{abstract}
BACKGROUND: The past 25 years have seen a substantial increase in the effect of specialty drugs on patient care. These agents were initially not considered financially viable because they often served a comparatively small market of patients. However, the extended monopoly afforded to manufacturers of these drugs by the Orphan Drug Act of 1983 has made treatment of rare diseases, which specialty drugs often target, a more viable option. As a result, pharmaceutical companies began to increase research and development expenditures in this area, and the pipeline of specialty drugs began to grow in the late 1980s.
\end{abstract}

OBJECTIVE: To analyze the annual change in wholesale acquisition cost (WAC) pricing of specialty drugs sold over a period of 11 years.

METHODS: Pharmacy claims data, including date and WAC, were collected for each specialty drug transaction that occurred from 2002 through 2013 at the University of Illinois at Chicago Ambulatory Care Pharmacy Department. The data were organized to create a chronological sequence of WAC values from the initial to final sales of each available drug. Those values were then used to calculate annual percentage of change in WAC. These results were grouped into subsets and graphed in order to illustrate the effects that various factors had on the annual changes in price.

RESULTS: The price of the specialty drugs studied has generally shown a greater rate of increase since experiencing a trough rate increase in 2009 of $4.08 \%$. The economic crisis of 2008 created a short pause in this overall trend, but increases in the rate of price growth have since rebounded. WACs increased at a rate of $7.03 \%$ or greater from 2010 through the end of the study period. There was a clear increase over the last few years of the study in the number of drugs with more than $10 \%$ annual increases in WAC, which has also shown a rebound after the economic crisis at the end of the last decade.

CONCLUSIONS: Specialty drugs are getting more expensive at a faster rate over time. The period from 2010 to 2013, the final year of this study, has also seen biologic agents take a more prominent role in driving these annual increases in WAC.

J Manag Care Spec Pharm. 2016;22(9):1010-17

Copyright $\odot 2016$, Academy of Managed Care Pharmacy. All rights reserved.

\section{What is already known about this subject}

The Orphan Drug Act of 1983 decreased regulatory requirements and increased financial incentives in order to make the development of drugs for the treatment of rare diseases a more financially viable proposition for drug manufacturers.

Specialty drugs now account for over a quarter of all drugs sold by dollar value.

Recently introduced specialty drugs have made news because of their high cost and high level of efficacy.

\section{What this study adds}

The annual increase in price of the average of all specialty drugs studied outpaces the general inflation rate.

The ratio of increase in specialty drug price as compared with the inflation rate has increased over the past 10 years.

Biologic products have become the primary drivers of price growth in the specialty drug category since 2010.

T here are no current established criteria defining what makes a drug a specialty pharmaceutical. Some factors that have been used to make this determination include the clinical application of the drug for a complex or rare disease, the requirement for special handling during transport or administration, a restricted or limited distribution, or the requirement for special patient monitoring for safety or efficacy. ${ }^{1,2}$ Conventional thought has associated this "specialty" designation with a drug's price, with a common monthly threshold cost of $\$ 600$ typically being used. ${ }^{1}$ Despite these various definitions, there has been general agreement concerning drugs that make up the specialty category.

The past 25 years have seen a substantial increase in the effect of specialty drugs on patient care. These agents, approximately $60 \%$ of which have orphan drug designations, were initially not considered financially viable because of the comparatively small market of patients these therapies often served. ${ }^{3,4}$ However, the extended monopoly afforded to manufacturers of these drugs by the Orphan Drug Act of 1983 has made treatment of these diseases a more lucrative option. ${ }^{5}$ This legislation was enacted by the U.S. government in response to increased awareness in the late 1970s and early 1980s of patients suffering from rare diseases. The Orphan Drug Act allowed for clinical studies to be performed with smaller patient populations because of the rarity of encountering the diseases and provided financial benefits, such as tax credits of $50 \%$ of clinical trial costs, market exclusivity for 7 years from the date of approval by the U.S. Food and Drug Administration (FDA), optional fast-track approval status, and waiving of user fees. ${ }^{6}$ As a result, pharmaceutical companies began to increase research and development expenditures in this area, and the pipeline of specialty drugs began to grow in the late 1980s. ${ }^{7}$ For example, in the 17 years before the Orphan Drug Act, the pharmaceutical industry 
sponsored 34 marketed orphan drugs, as opposed to the 39 orphan drugs brought to market in the 7 years following the legislation. ${ }^{8}$ Within 25 years of the enactment of the Orphan Drug Act, the FDA had granted 1,892 orphan designations to candidates in clinical trials and approved 326 orphan drugs for the market. ${ }^{9}$

By 1990, there were 10 FDA-approved therapies on the market that were considered specialty drugs. At that time, the total unit sales and dollar value represented only a small fraction of the total annual expenditures on pharmaceuticals. But, the model for developing drugs for orphan diseases profitably was established. The sequencing of the human genome and the explosion in biomedical technologies seen in the 1990s also served to increase the rate of development of novel specialty drug therapies. Specialty drugs accounted for $\$ 77.5$ billion, or about $24 \%$, of prescription drugs sold in the United States by 2011 , increasing to $\$ 87$ billion and 39\% by $2012 .{ }^{10-12}$

Newer specialty drugs treat a variety of complex chronic diseases, such as immune disorders, cancer, multiple sclerosis, and hepatitis C. Their use often requires special handling, administration, and monitoring, with annual costs of $\$ 10,000$ or more annually. ${ }^{10} \mathrm{~A}$ recent study found that the annual price increases of multiple sclerosis treatments, in particular, were growing at a rate that outpaced average prescription drug inflation by 5 - to 7 -fold and demonstrated price increases greater than other biologic agents. ${ }^{13}$ Specialty drugs are expected to continue this trend of representing an increasing percentage of units sold and dollars spent over the foreseeable future. A recent study predicted sales of specialty drugs to increase to $\$ 192$ billion by 2016 and $\$ 402$ billion and $47 \%$ of prescription drugs sold by $2020 .^{11,12}$ These figures are partly driven by the number of new specialty drugs released on the market annually. For example, every year since 2010, over half of the annual new drug approvals by the FDA have been specialty drugs. Another significant driver of this statistic is the continually increasing prices of specialty drugs. ${ }^{14}$

Wholesale acquisition cost (WAC) is presently the most accepted published benchmark value for the current market price of a pharmaceutical product. ${ }^{15}$ It has recognized inherent advantages over the previous reference pricing tool, average wholesale price (AWP), because of increased transparency and resulting trustworthiness. ${ }^{15-17}$ Although a subject of debate, WAC remains the most commonly accepted pharmaceutical pricing benchmark available in the United States. In order to better characterize pricing in the specialty drug market, we determined the annual percentage of change in WAC for all specialty medications sold over an 11-year period from the University of Illinois at Chicago Ambulatory Care Pharmacy Department, analyzed the change in this value over time, and performed a subgroup analysis that examined the effects of drug composition (small molecule vs. biologic) on this change.

\section{Methods}

\section{Collection of Prescription Claims Data}

The dataset used for this study was originally collected as the record of sale for specialty drugs sold by the University of Illinois at Chicago Ambulatory Care Pharmacy Department to its customers from 2002 through 2013. This record included the name of the drug sold, the date of the sale, the insurance coverage for the transaction, and price information, including WAC and AWP. The values used for the study were published prices only and included no rebate information. WAC values were determined by dividing published AWP values by a factor of 1.2. No additional information was collected from the customers during the course of this study, and data were de-identified before being evaluated; as such, this study was deemed exempt from institutional review board approval requirements.

\section{Evaluation of Data Used for Price Analysis}

In order to be used for WAC price trend analysis, data describing a customer transaction for a given drug had to be available for 30 consecutive months to ensure consistency of available data. This length of time ensured that at least 2 data points were available for annual percentage of WAC change in the dataset. When data for multiple formulations of a given drug were available, the formulation with the most data available was selected. To be included in the percentage of annual price change calculation for a given year, WAC data must have been available for at least 9 consecutive months in that year. This requirement was only used to determine which years to use as the first and final year of each drug dataset. For example, if the first calendar year of sales only included 7 months of data, that year was not used as the first year in the study. Instead, the data for the following year, with 12 consecutive months of data, would be used as the first year for analysis. If, alternatively, the first calendar year of data included 10 months of price data, it would be used for the first year of data for that drug. The same rules were instituted for inclusion and exclusion of the final year of data for a given drug. This was done to prevent an artificially low annual change in WAC resulting from data describing drugs only on the market for a short period in that year. If multiple WAC values were listed for a given month, the most common value was used for the study. The annual percentage of change in WAC was calculated for every drug that fit this criterion by subtracting the WAC value at the end of the year from the WAC value at the beginning of the year and dividing that number by the WAC value at the beginning of the year. Those values were then averaged to determine the average annual price change during the course of each year for all drugs included in the study. Drugs that did not fit this criterion for a given year were not included in the annual percentage price change calculation for that year.

The prescription claims data from $44 \mathrm{FDA}$-approved specialty drugs were used for the WAC price trend analyses (Table 1). 


\section{TABLE 1 Specialty Drugs Included in Study}

\begin{tabular}{|c|c|c|c|}
\hline Drug & Therapeutic Category & Structure & Company \\
\hline Darbepoetin alfa & Adjunctive & Biologic & Amgen \\
\hline Epoetin alfa & Adjunctive & Biologic & Jansen Biotech (J\&J) \\
\hline Certolizumab pegol & GI/rheum/sarc & Biologic & UCB \\
\hline Etanercept & GI/rheum/sarc & Biologic & Amgen \\
\hline Adalimumab & GI/rheum/sarc & Biologic & Abbvie \\
\hline Hyaluronic acid & GI/rheum/sarc & Biologic & Sanofi \\
\hline Tipranavir & HIV & Small molecule & Boehringer Ingelheim \\
\hline Emtricitabine/tenofovir/efavirenz & HIV & Small molecule & BMS \& Gilead \\
\hline Abacavir/lamivudine & HIV & Small molecule & ViiV Healthcare \\
\hline Etravirine & HIV & Small molecule & Tibotec (J\&J) \\
\hline Raltegravir & HIV & Small molecule & Merck \\
\hline Fosamprenavir & HIV & Small molecule & ViiV Healthcare \\
\hline Ritonavir & HIV & Small molecule & Abbvie \\
\hline Darunavir & HIV & Small molecule & Janssen \\
\hline Atazanavir & HIV & Small molecule & BMS \\
\hline Efavirenz & HIV & Small molecule & BMS \\
\hline Tenofovir/emtricitabine & HIV & Small molecule & Gilead \\
\hline Abacavir & HIV & Small molecule & ViiV Healthcare \\
\hline Entecavir & Liver & Small molecule & BMS \\
\hline Adefovir & Liver & Small molecule & Gilead \\
\hline Pegylated interferon alfa- $2 \mathrm{a}$ & Liver & Biologic & Genentech \& Roche \\
\hline Ribavirin & Liver & Small molecule & Merck \\
\hline Tenofovir & Liver & Small molecule & Gilead \\
\hline Rifaximin & Liver & Small molecule & Salix \\
\hline Interferon beta-la & MS & Biologic & Biogen Idec \\
\hline Interferon beta-lb & MS & Biologic & Bayer \\
\hline Glatiramer acetate & MS & Small molecule & Teva \\
\hline Fingolimod & MS & Small molecule & Novartis \\
\hline Interferon beta-la & MS & Biologic & Pfizer \\
\hline Cinacalcet & Nephrology & Small molecule & Amgen \\
\hline Imatinib & Oncology & Biologic & Novartis \\
\hline Leuprolide acetate & Oncology & Biologic & Abbvie \\
\hline Sorafenib & Oncology & Small molecule & Bayer \& Onyx \\
\hline Dasatinib & Oncology & Small molecule & BMS \\
\hline Erlotinib & Oncology & Small molecule & Astellas \& Genentech \\
\hline Thalidomide & Oncology & Small molecule & Celgene \\
\hline Capecitabine & Oncology & Small molecule & Genentech \\
\hline Palivizumab & Pediatrics & Biologic & Medimmune \\
\hline Sildenafil & Pulmonary & Small molecule & Pfizer \\
\hline Tobramycin & Pulmonary & Small molecule & Novartis \\
\hline Omalizumab & Pulmonary & Biologic & Genentech \& Novartis \\
\hline Mycophenolate mofetil & Transplant & Small molecule & Genentech \\
\hline Mycophenolate sodium & Transplant & Small molecule & Novartis \\
\hline Sirolimus & Transplant & Small molecule & Pfizer \\
\hline
\end{tabular}

Note: Data from 44 drugs were used for WAC analysis.

GI/rheum/sarc=gastrointestinal/rheumatology/sarcoid; HIV=human immunodeficiency virus; $M S=$ multiple sclerosis; WAC=wholesale acquisition cost.

These drugs were categorized according to primary field of application, including adjunctive, gastrointestinal/rheumatology/sarcoid, human immunodeficiency virus, liver, multiple sclerosis, nephrology, oncology, pediatrics, pulmonary, and transplant. The WAC pricing data were collected for each month that the drug was sold at the pharmacy, and the percentage of change from the previous month's price was determined as previously described. After determining the annual percentage of change in drug price, that value was averaged for each therapeutic group, and the data for each year studied were graphed. 


\section{FIGURE 1 Modulation in the Rate of WAC Price Changes over Time}

\section{A. Annual Percentage of WAC Change for Specialty Drugs}

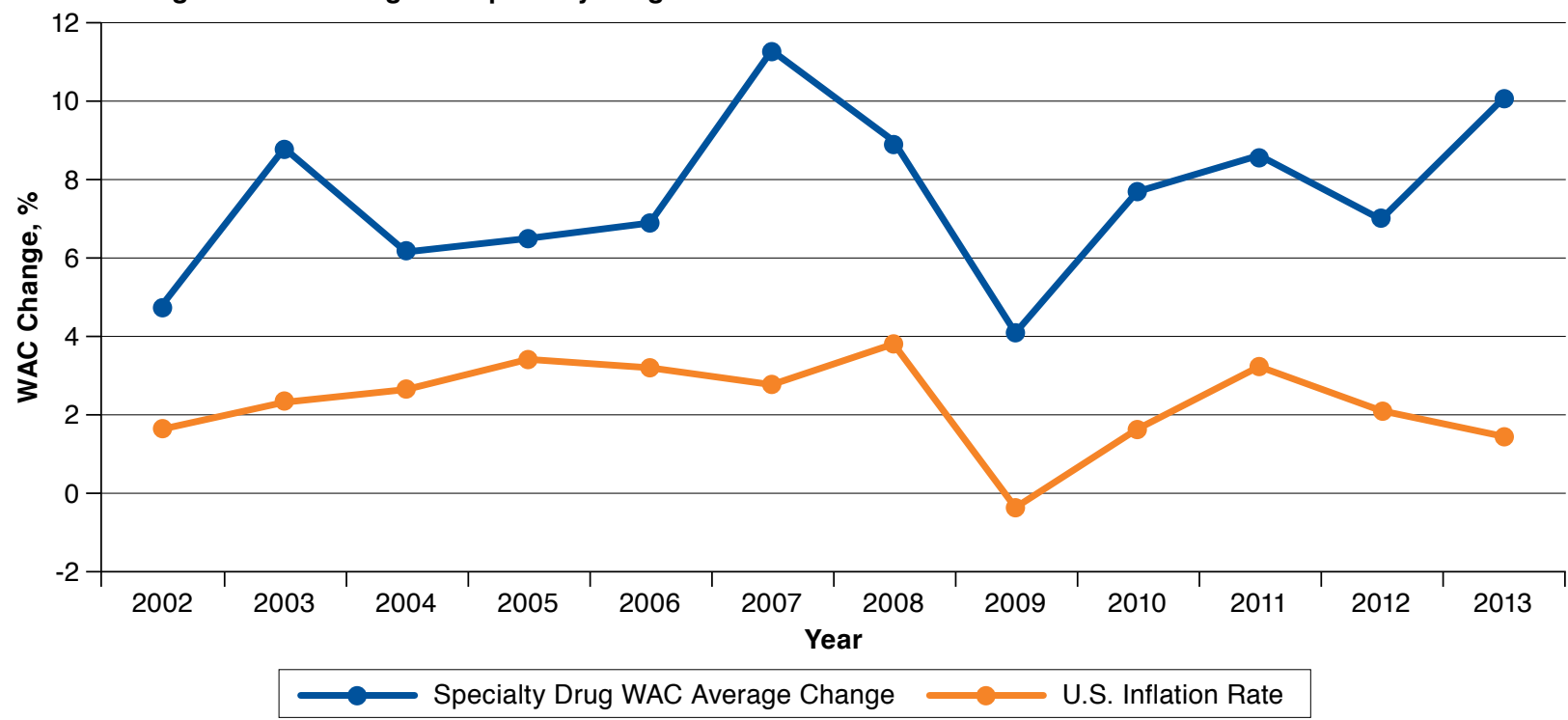

\section{B. Ratio of Specialty Drug WAC Average Change to Inflation Rate}

\begin{tabular}{|c|c|c|c|c|c|c|c|c|c|c|c|}
\hline $\mathbf{2 0 0 2}$ & $\mathbf{2 0 0 3}$ & $\mathbf{2 0 0 4}$ & $\mathbf{2 0 0 5}$ & $\mathbf{2 0 0 6}$ & $\mathbf{2 0 0 7}$ & $\mathbf{2 0 0 8}$ & $\mathbf{2 0 0 9}$ & $\mathbf{2 0 1 0}$ & $\mathbf{2 0 1 1}$ & $\mathbf{2 0 1 2}$ & $\mathbf{2 0 1 3}$ \\
\hline 3.03 & 3.83 & 2.28 & 1.91 & 2.15 & 4.03 & 2.36 & $-10.20^{\mathrm{a}}$ & 4.85 & 2.71 & 3.35 & 6.71 \\
\hline
\end{tabular}

\section{Number of Drugs with Significant Year-on-Year WAC Increases}

\begin{tabular}{|c|c|c|c|c|}
\hline Year & $>\mathbf{1 0}$ Increase & $\mathbf{2 0}$ Increase & $\mathbf{> 3 0 \%}$ Increase & $\mathbf{> 5 0}$ Increase \\
\hline 2002 & 2 & 1 & 1 & 0 \\
\hline 2003 & 3 & 1 & 1 & 1 \\
\hline 2004 & 4 & 1 & 0 & 0 \\
\hline 2005 & 4 & 1 & 1 & 1 \\
\hline 2006 & 7 & 1 & 0 & 0 \\
\hline 2007 & 11 & 5 & 2 & 1 \\
\hline 2008 & 12 & 0 & 0 & 0 \\
\hline 2009 & 4 & 0 & 0 & 0 \\
\hline 2010 & 7 & 3 & 1 & 1 \\
\hline 2011 & 12 & 1 & 0 & 0 \\
\hline 2012 & 10 & 3 & 0 & 0 \\
\hline 2013 & 14 & 4 & 0 & 0 \\
\hline
\end{tabular}

\section{Drugs with the Highest Year-on-Year Percentage of Increase in WAC}

\begin{tabular}{|c|c|c|c|c|}
\hline Year & Drug & WAC Increase, $\%$ & Therapeutic Category & Company \\
\hline 2002 & Thalidomide & 30.14 & Oncology & Celgene \\
\hline 2003 & Thalidomide & 79.78 & Oncology & Celgene \\
\hline 2004 & Thalidomide & 29.88 & Oncology & Celgene \\
\hline 2005 & Thalidomide & 59.82 & Oncology & Celgene \\
\hline 2006 & Thalidomide & 27.94 & Oncology & Genentech \& Novartis \\
\hline 2007 & Omalizumab & 53.04 & Transplant & Genentech \\
\hline 2008 & Mycophenolate mofetil & 19.80 & Oncology & Salix \\
\hline 2009 & Capecitabine & 19.80 & Liver & Salix \\
\hline 2010 & Rifaximin & 60.00 & MS & Biogen Idec \\
\hline 2011 & Rifaximin & 20.01 & GI/rheum/sarc & UCB \\
\hline 2012 & Interferon beta la & 25.36 & 25.90 &
\end{tabular}

aThe negative value seen for 2009 is the result of having a negative inflation rate for the year.

$\mathrm{GI} /$ rheum/sarc = gastrointestinal/rheumatology/sarcoid; MS = multiple sclerosis; WAC = wholesale acquisition cost. 


\section{FIGURE 2 WAC Price Changes over First 3 Years of Sales}

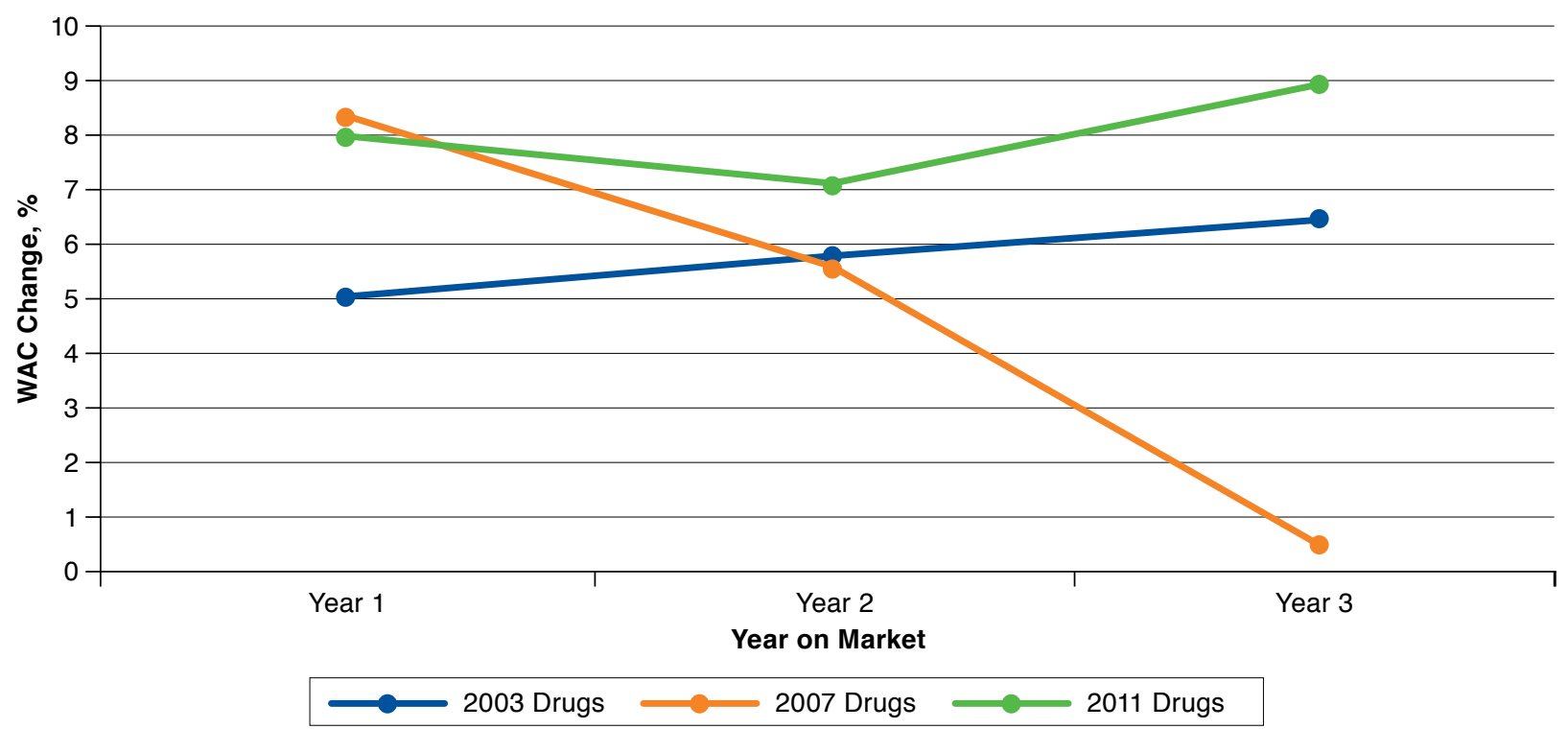

Note: All drugs that were first available in 2003 were identified, and their percentage of change in WAC values were averaged for 2003 (year 1), 2004 (year 2), and 2005 (year 3). For example, the percentage of change in WAC for each of adalimumab, adefovir, peginterferon alfa-2a over the course of their first year on the market was calculated and averaged for the 3 drugs. This value was graphed as the first blue dot. The same calculation was done for their second year on the market (in 2004) and their third year on the market (in 2005), which were plotted as the second and third blue dots. This process was repeated for drugs starting in years 2007 and 2011. WAC $=$ wholesale acquisition cost.

\section{Results}

Figure 1A shows the average annual percentage of change in WAC for all specialty drugs sold in comparison to the average rate of inflation. ${ }^{18}$ The percentage of change in WAC for specialty drugs was greater than the rate of inflation for every year studied. With the exception of a temporary spike in WAC growth seen in 2003, there is a gradual annual increasing percentage of WAC change from 2002 through 2006. There is another sharp increase seen in 2007 , followed by a decreasing trend through 2009 , the year with the lowest annual WAC increase. The end of the graph shows some variability in 2012 but demonstrates steady increases in WAC through the end of the period studied. The inflation rate baseline demonstrates that price increases in the latter half of the 12-year span are more significant in relation to the general economy (Figure 1B). The years with the smallest percentage of change relative to inflation are 2005 and 2006, when the WAC increase was 1.91 and 2.15 times the inflation rate, respectively. The year with the greatest disparity was 2013, with a 6.71-fold difference between WAC percentage of change and inflation rate. No other year had a greater than 5-fold difference. Interestingly, also in 2013, the change in WAC was able to overcome a decrease in overall inflation rate to achieve a value of just over $10 \%$. The only period that was able to sustain 3 years or more of WAC growth greater than 2.5 times the inflation rate was the final 4 years of the study, from 2010 through 2013.

The evolution of specialty drug pricing can also be seen via the number of drugs in a given year that experienced significant price increases over the previous year. We identified the drugs each year that demonstrated price increases of $>10 \%$, $>20 \%,>30 \%$, and $>50 \%$ over the previous year and tallied that data in Figure 1C. Of note, there were no drugs demonstrating an annual change in WAC greater than 20\% in 2008 and 2009. At the other extreme, 1 drug achieved a greater than 50\% increase in WAC in 2003, 2005, 2007, and 2010. The years showing more than 10 drugs with greater than $10 \%$ change in WAC included 2007, 2008, 2011, 2012, and 2013. The year 2013 saw the greatest number of drugs with $>10 \%$ increases in WAC, illustrating a more systemic effect of price increases during that year.

The drug with the greatest percentage of increase in WAC during each year studied was identified and listed in Figure 1D. Thalidomide was the most common drug on this list, capturing the highest rate of increase during the years 2002 through 2006. Thalidomide achieved its greatest increase in 2003, which at $79.78 \%$ was the greatest annual percentage of increase of any drug studied. The only other drug that made the list 


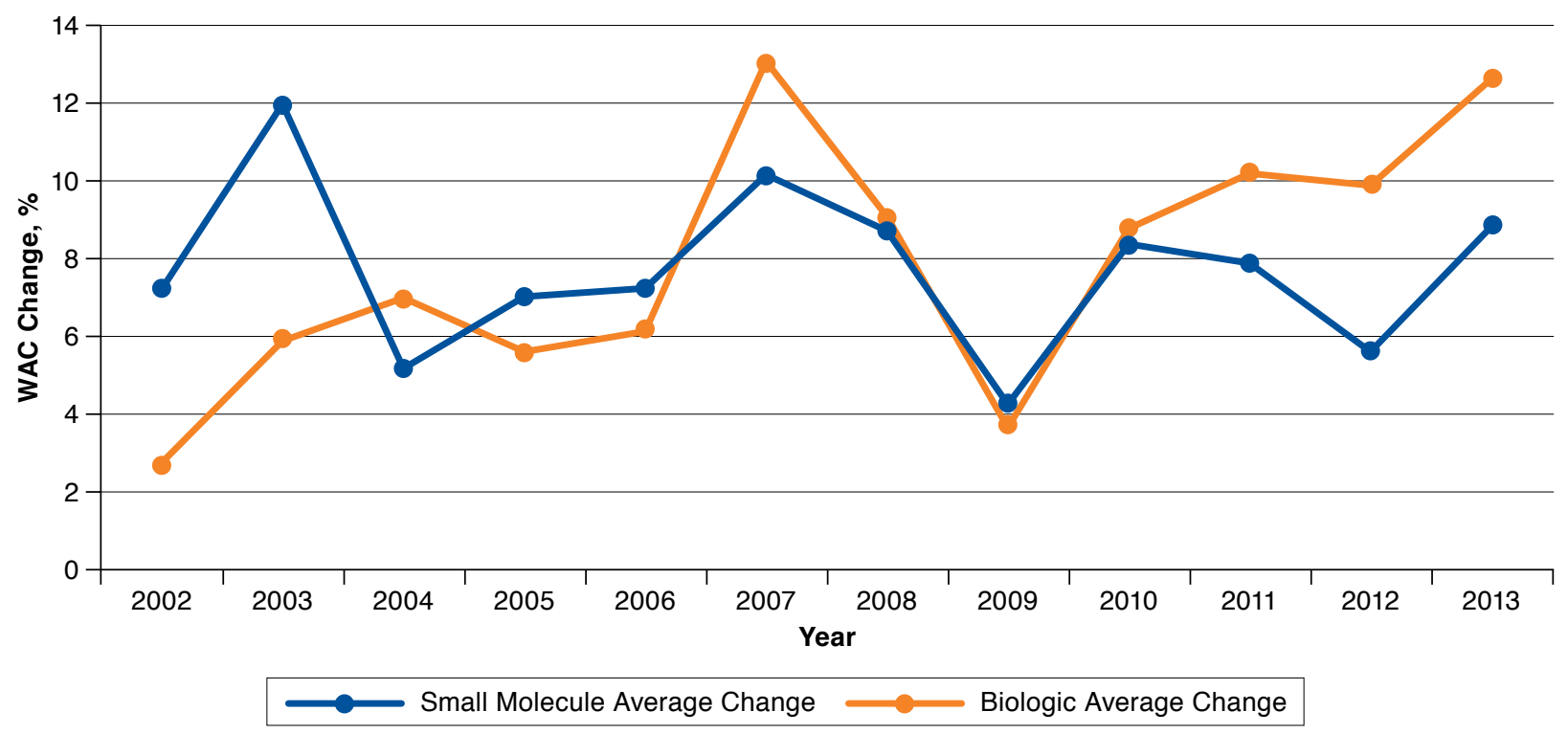

WAC = wholesale acquisition cost.

on 2 occasions was rifaximin, which had increases of $60 \%$ in 2010 and 20.01\% in 2011. Overall, there were 4 years during which the percentage of change in WAC was greater than $50 \%$ : thalidomide in 2003 (79.78\%), thalidomide in 2005 (59.82\%), omalizumab in 2007 (53.04\%), and rifaxamin in 2010 (60\%).

A subgroup analysis was also performed in which average percentage of WAC increases occurring only during the first 3 years of a sale for a newly marketed drug were compared. In this evaluation, drugs that entered the market starting in 2003 (adalimumab, adefovir, and peginterferon alfa-2a), were compared with drugs released in 2007 (efavirenz/emtricitabine/ tenofovir and atazanavir) and those starting in 2011 (etravirine, glatiramer, and fingolimod). The results of this analysis are shown in Figure 2. This figure shows that drugs introduced to the market in 2003 maintained a relatively moderate, but steady, increase in WAC during their first 3 years, starting at $5.02 \%$ and rising to $6.44 \%$ by year 3 . The second group, which entered the market in 2007, started off with the highest first year average rate increase of any of the groups. However, the rate of increase fell distinctly during the subsequent 2 years (2008 and 2009). The third group, made up of drugs introduced in 2011, showed a similar trend as the drugs first marketed in 2003. Most importantly, the final group demonstrated the most significant growth of the groups studied, starting with a rate of $7.93 \%$ in 2011 and finishing with $8.90 \%$ in 2013 .

A comparison of the average percentage of change in WAC for the 31 small molecule specialty drugs versus the 13 biologic specialty drugs used in this study can be seen in Figure 3.
To clarify, small molecule agents are considered to be those compounds that are less than 1,000 Da in size and exert their therapeutic effect through the modulation of a specific biologic target, whereas biologicals are proteins derived from living cells and are thus larger in size $(5-200 \mathrm{kDa})$ and possess the potential for more complex mechanisms of action. ${ }^{19}$ The data in Figure 3 essentially fell into 3 segments. The first segment showed significantly greater increases in the WAC of small molecule drugs, during which they had 2.70-fold and 2.04-fold greater WAC increases than biologics. The second segment spans years 2004-2010, during which the 2 categories were separated by no more than 1.35-fold, which occurred in 2004. In the final segment, years 2011-2013, the biologic agents began to take the lead in WAC growth with differences of 1.3-fold, 1.75-fold, and 1.43-fold for the final 3 years of the study.

\section{Discussion}

The overall pharmaceutical market in the United States is expected to continue growing at greater than 10\% per year and soon be worth $\$ 400$ billion per year, with the worldwide pharmaceutical market soon expected to reach a value of $\$ 1$ trillion. ${ }^{20,21}$ While far from being the only driver, the specialty drug market has become a significant subset of the overall pharmaceutical therapeutics market. ${ }^{22}$ As a result, this sector has become a focus of drug research and development activities, which benefits patients, especially those suffering from orphan diseases. These patients have received life-saving or life-changing treatments, when just a few years ago there was 
often nothing available. However, the cost of these agents has been the source of significant concern and study. ${ }^{23-27}$

The markets for specialty drug therapies and the compositions themselves possess key differences from traditional drug therapies, including market size and molecular complexity, which can ultimately affect the pricing of those products. The data from this study cannot inform the appropriateness of the price increases shown; instead, the data were intended to identify how pricing has changed during this period of growth in the specialty drug market. Additional studies need to be performed in order to identify what pricing is warranted and when that price should be increased to better address changing market factors. ${ }^{28}$ Patients and their ability to afford a medication also need to be considered. At what point does the physical enablement of a treatment become overshadowed by the fiscal disablement it has for the purchaser? What influence should insurance companies have in the final determination of price and price changes?

Our data show a trend of steady growth in the annual change in WAC from 2002 through 2006 and continuing from 2010 through 2013, the final year that data were collected. This trend is interrupted first by a significant increase in the change in WAC in 2007, followed by a sharp downturn in 2007 and 2008. This decrease mimics U.S. inflation rate and likely is the result of the general economic downturn. This trend carries through every analysis performed in this study. It appears that the economic downturn reset the increasing WAC rate for a few years, but now it has recovered. We highlighted the fact that even though the increasing trend in WAC has been steady, with the exception of the period from 2007 through 2009, the nature of the driver of this increase has changed over time. For example, biologic agents have become the driver of specialty pharmaceutical price increases over the past few years.

One of the factors that has been an upward pressure in the pricing of biologic agents has been the lack of a pathway for FDA approval of biosimilar competition. Until now, the innovating therapy has been given a de facto permanent monopoly for sale of that agent. This may soon be about to change, however. In March 2015, the FDA approved the first U.S. biosimilar agent: filgrastim-sndz (Zarxio, Sandoz). ${ }^{29}$ The entry of biosimilars may make the rapidly growing biologics market behave more similarly to the small molecule market. Alternatively, it may also encourage much greater year-on-year price increases for biologic specialty drugs in order to allow sellers to recoup their very large investments for drugs that serve comparatively few patients.

The specialty drug market, and its potential for profit, is currently an area of focus for many pharmaceutical companies. ${ }^{30,31}$ This has resulted in the development of life-saving medications and increased cost pressures on all payers. Both of these factors have and will continue to be the source of controversy and discussion in medical, financial, and political arenas.

\section{Limitations}

This study combines data from the sales transactions of a diverse set of drugs in order to identify the trends in that data over time. Since this analysis is based on a heterogeneous population, it does not lend itself to commonly used statistical analysis. We determined the true value of these findings from these emerging trends and decided not to implement strict statistical analysis. While our goal was not to define a specific population set, the lack of statistics is a limitation.

Our dataset was based on the sales transactions of a single pharmacy group, which is a limitation to our findings. If a larger dataset was readily available, we could have included a wider variety of drugs in our study and potentially included every monthly WAC value for which a given drug was available on the market.

Our dataset was also limited by time. It would have been ideal to have data from the sale of specialty drugs since their first introduction to the market through to the present day. We could then better compare the full range of annual price changes of not just the entire group of drugs but also within therapeutic classes in order to provide a more complete evolution of the pricing of specialty drugs.

\section{Conclusions}

Specialty drugs are getting more expensive at a faster rate over time. The period from 2010 to 2013, the final year of this study, saw biologic agents take a more prominent role in driving these annual increases in WAC.

\section{Authors}

ROBERT PENINGTON, PharmD, MS, MBA, and JO ANN STUBBINGS, BSPharm, MHCA, University of Illinois at Chicago College of Pharmacy, Chicago, Illinois.

AUTHOR CORRESPONDENCE: Jo Ann Stubbings, BSPharm, MHCA, University of Illinois at Chicago College of Pharmacy, 840 S. Wood St., MC 884, Chicago, IL 60612. Tel.: 312.996.3098; Fax: 312.355.1916; E-mail: joanns@uic.edu.

\section{DISCLOSURES}

No funding was provided for the commission of this study. The source data was provided by the University of Illinois at Chicago Ambulatory Care Pharmacy Department and described de-identified data from customer transactions from 2002 through 2013. The authors report no conflicts of interest.

Study concept and design and data interpretation were contributed by Stubbings and Penington. The manuscript was written primarily by Penington with assistance from Stubbings. 


\section{REFERENCES}

1. Spatz I, Mcgee N. Health Policy Brief: Specialty pharmaceuticals. Health Affairs. November 25, 2013. Available at: http://www.healthaffairs.org/ healthpolicybriefs/brief.php?brief_id=103. Accessed August 10, 2016.

2. Hagerman J, Freed S, Rice G. Specialty pharmacy: a unique and growing industry. American Pharmacists Association. July 1, 2013. Available at: http://www.pharmacist.com/specialty-pharmacy-unique-and-growingindustry. Accessed August 10, 2016.

3. CVS Specialty. Comprehensive specialty pharmacy drug list. July 2016. Available at: https://www.cvsspecialty.com/wps/wcm/connect/d5405d7b-685e4377-b998-2e4c4dafob13/SpecialtyDrugs.pdf?MOD=AJPERES\&CACHEID= d5405d7b-685e-4377-b998-2e4c4daf0b13. Accessed August 10, 2016.

4. U.S. Food and Drug Administration. Search orphan drug designations and approvals. Available at: http://www.accessdata.fda.gov/scripts/opdlisting/oopd/. Accessed August 10, 2016.

5. Meekings KN, Williams CS, Arrowsmith JE. Orphan drug development: an economically viable strategy for biopharma R\&D. Drug Discov Today. 2012;17(13-14):660-64.

6. Kesselheim A. Appendix B: Innovation and the Orphan Drug Act, 19832009: regulatory and clinical characteristics of approved orphan drugs. In: Institute of Medicine, Committee on Accelerating Rare Diseases Research and Orphan Product Development; Field MJ, Boat TF, eds. Rare Diseases and Orphan Products: Accelerating Research and Development. Washington, DC: National Academies Press; 2010. Available at: http://www.ncbi.nlm.nih.gov/ books/NBK56187/. Accessed August 10, 2016.

7. Seoane-Vazquez E, Rodriguez-Monguio R, Szeinbach SL, Visaria J. Incentives for orphan drug research and development in the United States. Orphanet J Rare Dis. 2008;16;3:33. Available at: http://www.ncbi.nlm.nih. gov/pmc/articles/PMC2631478/. Accessed August 10, 2016.

8. Asbury CH. The Orphan Drug Act. The first 7 years. JAMA. 1991;265(7):893-97.

9. Braun MM, Farag-El-Massah S, Xu K, Coté TR. Emergence of orphan drugs in the United States: a quantitative assessment of the first 25 years. Nat Rev Drug Discov. 2010;9(7):519-22.

10. Specialty pharmaceuticals: facts, figures and trends executive summary. Specialty Pharma Journal. 2012. Available at: http://www.specialtypharmajournal.com/medical-news/business-news/3554-specialty-pharmaceuticalsfacts-figures-and-trends-executive-summary. Accessed August 10, 2016.

11. UnitedHealth Center for Health Reform \& Modernation. The growth of specialty pharmacy: current trends and future opportunities. April 2014. Available at: http://www.unitedhealthgroup.com/ /media/UHG/PDF/2014/ UNH-The-Growth-Of-Specialty-Pharmacy.ashx. Accessed August 18, 2016.

12. Pharmaceutical Strategies Group. Press release. Pharmaceutical Strategies Group to detail how to better control pharmacy benefit, specialty drug costs at ASHHRA conference. Business Wire. September 18, 2015. Available at: http://www.businesswire.com/news/home/20150918005132/ en/Pharmaceutical-Strategies-Group-Detail-Control-Pharmacy-Benefit. Accessed August 18, 2016

13. Hartung DM, Bourdette DN, Ahmed SM, Whitham RH. The cost of multiple sclerosis drugs in the US and the pharmaceutical industry: too big to fail? Neurology. 2015;84(21):2185-92. Available at: http://www.ncbi.nlm.nih. gov/pmc/articles/PMC4451044/. Accessed August 10, 2016.

14. Lotvin AM, Shrank WH, Singh SC, Falit BP, Brennan TA. Specialty medications: traditional and novel tools can address rising spending on these costly drugs. Health Aff (Millwood). 2014;33(10):1736-44.

15. Academy of Managed Care Pharmacy. AMCP guide to pharmaceutical payment methods (version 3.0). 2013. Available at: http://www.amcp.org/ pharmaceutical-payment-guide/. Accessed August 10, 2016.
16. Gencarelli DM. Average wholesale price for prescription drugs: is there a more appropriate pricing mechanism? NHPF Issue Brief. 2002;(775):1-19. Available at: https://www.nhpf.org/library/issue-briefs/IB775_AWP_6-7-02.pdf. Accessed August 10, 2016.

17. Curtiss FR, Lettrich P, Fairman KA. What is the price benchmark to replace average wholesale price (AWP)? J Manag Care Pharm. 2010;16(7): 492-501. Available at: http://www.jmcp.org/doi/10.18553/jmcp.2010.16.7.492.

18. Historical inflation rates: 1914-2015. U.S. Inflation Calculater. Available at: http://www.usinflationcalculator.com/inflation/historical-inflation-rates/. Accessed August 8, 2015.

19. Pharmacy Practice News. Special report: understanding key differences between biosimilars and small molecule generics. May 2013. Available at: http://www.pharmacypracticenews.com/download/sr1229_wm.pdf. Accessed August 10, 2016.

20. U.S. pharma market will top $\$ 377$ billion in 2014; up 11-13\%. Pharmaceutical Commerce. November 20, 2014. Available at: http://pharmaceuticalcommerce.com/latest_news?articleid=27416. Accessed August 10, 2016.

21. Herper M. Why big pharma won't get its piece of the $\$ 1.2$ trillion global drug market. Forbes. July 12, 2012. Available at: http://www.forbes.com/ sites/matthewherper/2012/07/12/the-global-drug-market-will-swell-to1-2-trillion-while-big-pharma-treads-water/\#3eef3e9bl3fb. Accessed August 10, 2016.

22. Fein AJ. Diplomat shows specialty pharmacy's profits and infusion's promise. Drug Channels. March 24, 2015. Available at: http://www. drugchannels.net/2015/03/diplomat-shows-specialty-pharmacys.html. Accessed August 10, 2016

23. Kunze AM, Gunderson BW, Gleason PP, Heaton AH, Johnson SV. Utilization, cost trends, and member cost-share for self-injectable multiple sclerosis drugs - pharmacy and medical benefit spending from 2004 through 2007. J Manag Care Pharm. 2007;13(9):799-806. Available at: http:// www.jmcp.org/doi/abs/10.18553/jmcp.2007.13.9.799.

24. Tegenu M. Health plan approach to operationalizing a specialty drug management program. J Manag Care Pharm. 2008;14(4 Suppl A):S17-21. Available at: http://www.jmcp.org/doi/pdf/10.18553/jmcp.2008.14.S4-A.17.

25. Navarro RP, Johnson KA. Opportunities and challenges of specialty pharmaceuticals. J Manag Care Pharm. 2013;19(1):70-71. Available at: http:// www.jmcp.org/doi/10.18553/jmcp.2013.19.1.70.

26. Gleason PP, Alexander GC, Starner CI, et al. Health plan utilization and costs of specialty drugs within 4 chronic conditions. J Manag Care Pharm. 2013;19(7):542-48. Available at: http://www.jmcp.org/doi/10.18553/ jmcp.2013.19.7.542.

27. Kaisaeng N, Harpe SE, Carroll NV. Out-of-pocket costs and oral cancer medication discontinuation in the elderly. J Manag Care Spec Pharm. 2014;20(7):669-75. Available at: http://www.jmcp.org/doi/10.18553/ jmcp.2014.20.7.669.

28. Sullivan SD. The promise of specialty pharmaceuticals: Are they worth the price? J Manag Care Pharm. 2008;14(4 Suppl A):S3-6. Available at: http:// www.jmcp.org/doi/abs/10.18553/jmcp.2008.14.S4-A.3.

29. U.S. Food and Drug Administration. FDA news release. FDA approves first biosimilar product Zarxio. March 6, 2015. Available at: http://www. fda.gov/NewsEvents/Newsroom/PressAnnouncements/ucm436648.htm. Accessed August 10, 2016.

30. Kober S. The evolution of specialty pharmacy. Biotechnol Healthc. 2008;5(2):50-51.

31. Tharaldson A. Pipeline update: anticipated specialty drug approvals. Express Scripts: The Lab. September 25, 2014. Available at: http://lab. express-scripts.com/insights/drug-options/pipeline-update-anticipatedspecialty-drug-approvals. Accessed August 10, 2016. 